\title{
Altered ependyma and leptomeninges in transgenic mice that over express FGF2 and amyloid precursor protein: evidence for early hydrocephalus
}

\author{
Edward Stopa*1, Miles Miller ${ }^{1}$, Eddie Blay¹, Paul McMillan'1, \\ Douglas Coffin $^{2}$, Andrew Baird ${ }^{3}$, John Donahue ${ }^{1}$ and Conrad Johanson ${ }^{1}$
}

\author{
Email: Edward Stopa* - EStopa@lifespan.org \\ * Corresponding author \\ from 52nd Annual Meeting of the Society for Research into Hydrocephalus and Spina Bifida \\ Providence, RI, USA. I I-I4 June 2008 \\ Published: 3 February 2009 \\ Cerebrospinal Fluid Research 2009, 6(Suppl I):S4 doi:I0.II86/I743-8454-6-SI-S4
}

Address: ${ }^{1}$ Neuropatholgy and Clinical Neuroscience, Brown Medical School, Providence, Rhode Island 02903, USA, ${ }^{2}$ Montana Cancer Institute Foundation, University of Montana, Missoula, MT, USA and ${ }^{3}$ Pharmacy School, University of California San Diego, San Diego, CA, USA

This abstract is available from: http://www.cerebrospinalfluidresearch.com/content/6/SI/S4

(C) 2009 Stopa et al; licensee BioMed Central Ltd.

\begin{abstract}
Background
Disruption of CNS microvessels and CSF-bordering cells (ependyma, choroid plexus and leptomeninges) can alter fluid flow among the CNS compartments. This leads to hydrocephalus. An excess of basic fibroblast growth factor (FGF2) or amyloid precursor protein (APP), from which A-Beta fragments derive, predisposes to altered fluid dynamics and amyloid retention. We combined these risk factors to accelerate development of hydrocephalus. Hypothesis: Doubly-transgenic animals, overexpressed for FGF2 and APP, have greater morbidity in respect to compromised CSF turnover and toxic A-Beta effects. We also postulated CSF/brain and blood/brain interfaces to be especially vulnerable in double overexpression.
\end{abstract}

\section{Materials and methods}

One of us (D.C.) bred pairs of TgFGF2 $\times$ TgAPP to generate TgFGF2, TgAPP and TgFGF2 $\times$ TgAPP mice with variable degrees of FGF2 and A-Beta concentrations in CNS. Brain tissue specimens from 3-month old mice were split by sagittal cutting into two hemispheres. One half was snap-frozen in liquid nitrogen; the other half fixed in $4 \%$ paraformaldehyde in $0.1 \mathrm{M}$ sodium phosphate. Each cerebral hemisphere was subject to a coronal cut. The anterior commissure and posterior limit of the optic chiasm served as landmarks for sectioning. A freezing microtome was used to cut 10 -micron sections from the caudal por- tion. Tissue samples were analyzed by standard histochemical techniques published by our Neuropathology and Neurosurgery laboratories.

\section{Results and conclusion}

Thioflavin S fluorescent staining revealed greater A-Beta deposits at 3 mo in neuronal cytoplasm and microvessel walls in TgAPP $\times$ FGF2 than in TgAPP $\times$ FGF2 knockout (KO) mice. For the A-Beta1-42 immunostaining, both TgAPP $\times$ TgFGF2 and TgAPP $\times$ FGF2KO mice had plaques, but there was greater A-Beta1-42 staining in the neuronal cytoplasm of the former. For FGF2 immunostaining, in the TgAPP/TgFGF2 overexpressor animals there was more neuronal signal than in TgAPP/TgFGF2KO mice. The most striking histological finding in TgAPP $\times$ TgFGF2 overexpression was flattened and denuded ependyma characteristic of early-onset hydrocephalus. These findings are reminiscent of the ventriculomegaly and disrupted ependyma previously found in rats infused intracerebroventricularly with FGF2 [1]. Collectively, our animal models indicate that excesses of FGF2 and A-Beta fragments in the brain enhance the morbidity and mortality of rodents. The homeostasis of CSF and brain interstitial fluid is disrupted when ependymal, meningeal and vascular/brain interfaces are damaged. These factors likely contribute to destabilizing effects of chronic hydrocephalus. [Sup- 
ported by a grant from the Alzheimer's Association to E.S. and C.J]

\section{References}

I. Johanson C, Szmydynger-Chodobska J, Chodobski A, Baird A, McMillan P, Stopa EG: Altered formation and bulk absorption of cerebrospinal fluid in FGF-2-induced hydrocephalus. Am J Physiol 1999, 277:R263-R27|

Publish with Bio Med Central and every scientist can read your work free of charge

"BioMed Central will be the most significant development for disseminating the results of biomedical research in our lifetime. " Sir Paul Nurse, Cancer Research UK

Your research papers will be:

- available free of charge to the entire biomedical community

- peer reviewed and published immediately upon acceptance

- cited in PubMed and archived on PubMed Central

- yours - you keep the copyright

Submit your manuscript here:

http://www.biomedcentral.com/info/publishing_adv.asp 